\title{
Carbon Dioxide Reactivity of the Cerebral Circulation in Extremely Premature Infants: Effects of Postnatal Age and Indomethacin
}

\author{
MALCOLM I. LEVENE, DAVID SHORTLAND, N. GIBSON, AND DAVID H. EVANS
}

Department of Child Health and Medical Physics [D. H. E.], Leicester University School of Medicine, Leicester

Royal Infirmary, Leicester LE1 5WW, England

\begin{abstract}
Little is known about the vasoactivity of cerebral arterioles in extremely premature infants. We have assessed the effects of a small rise in $\mathrm{PaCO}_{2}$ of $1 \mathrm{kPa}$ $(7.5 \mathrm{~mm} \mathrm{Hg}$ ) on cerebral blood flow velocity measured by duplex Doppler ultrasound. Nineteen mechanically ventilated infants of 33 wk gestational age or less in whom direct arterial blood pressure monitoring was available, were studied on 45 occasions. There was a close relationship between increasing $\mathrm{PaCO}_{2}$ and increasing cerebral blood flow velocity $(p<0.005)$ but on seven of 45 occasions the cerebral blood flow velocity fell with rising $\mathrm{PaCO}_{2}$. There was a $44 \%$ (median value) rise in cerebral blood flow velocity per $1 \mathrm{kPa}$ rise in $\mathrm{PaCO}_{2}(5.9 \% / 1 \mathrm{~mm} \mathrm{Hg})$ in 21 infants tested within $24 \mathrm{~h}$ of birth and this increased to a $53 \%$ (median value) rise $(7 \% / 1 \mathrm{~mm} \mathrm{Hg}$ ) in 20 infants tested after $24 \mathrm{~h}(p<0.001)$. Eleven infants had paired studies, the first within $24 \mathrm{~h}$ and a second at a median age of $48 \mathrm{~h}$. There was a statistically significant increase in percentage reactivity when the later group was compared to those tested within $24 \mathrm{~h}(\mathrm{p}<0.001)$. Carbon dioxide reactivity was also assessed before and after indomethacin infusion $(0.2 \mathrm{mg} / \mathrm{kg})$ on four occasions and there was a reduction in reactivity from a median value of 144 to $49.5 \%$, $10 \mathrm{~min}$ after indomethacin. The extremely immature, ill infant is less sensitive to a small change in $\mathrm{PaCO}_{2}$ within $24 \mathrm{~h}$ of birth and after indomethacin infusion. We speculate that this may be related to a state of relative arteriolar vasoconstriction compared with infants 24 h or more after birth and those not influenced by the vasoconstrictor properties of indomethacin. (Pediatr Res 24: 175-179, 1988)
\end{abstract}

\section{Abbreviations}

CBF, cerebral blood flow

CBFV, cerebral blood flow velocity

MAP, mean arterial blood pressure

PVH, periventricular hemorrhage

The control of $\mathrm{CBF}$ is mediated through the cerebral arterioles that vasodilate or constrict in response to the local chemical environment or changes in perfusion pressure. In the premature infant, little is known about the integrity of these vessels. It has been shown that a varaiety of mammalian species can autoregulate their $\mathrm{CBF}$ at, or shortly after birth, including lambs (1, 2 ), piglets (3), and dogs (4) but there is no convincing data

Received December 15, 1987; accepted March 29, 1988.

Correspondence Dr. Malcolm I. Levene, Neonatal Unit, Department of Child Health, Leicester Royal Infirmary, Leicester LE1 5WW, England.

Supported by the Spastics Society and Leicestershire District Locally Organized Research. showing that the newborn human infant has this control. Arteriole vasoactivity depends on developed and functioning muscle within the vessel wall and although it may be present anatomically, there is little information as to when it becomes functionally active.

Arterial carbon dioxide tension is a potent mediator of arteriolar tone; increasing $\mathrm{PaCO}_{2}$ dilates the vessel and reduced $\mathrm{PaCO}_{2}$ causes the vessel to constrict. We have previously shown there to be consistent changes in Doppler recordings from the anterior cerebral artery of the healthy full-term infant with increasing end tidal $\mathrm{CO}_{2}(5)$. This method may also be used to investigate if the critically ill preterm infant is capable of reacting to the same stimulus. We have attempted to assess if the ill, mechanically ventilated, premature infant can change his CBFV in response to a changing $\mathrm{PaCO}_{2}$ and this may give further information on the functional integrity of the cerebral arterioles.

\section{METHODS}

Carbon dioxide reactivity tests were performed on premature infants of $33 \mathrm{wk}$ gestational age or less, if they required mechanical ventilation. All mechanically ventilated infants had direct blood pressure monitoring via an umbilical artery catheter (tip situated at the level of the diaphragm) or a peripheral artery (radial or positerior tibial) cannula connected to a pressure transducer. Systolic, diastolic, and MAP was measured directly by a pressure transducer connected via noncompliant manometer tubing to the arterial line. The frequency response of this system has been previously reported (6). A permanent recording of blood pressure was made onto continuous paper strip.

The study was approved by the Leicestershire District Ethical Committee. All infants were studied on the first day of life and further studies were performed when possible. Arterial blood gas estimate of $\mathrm{PaCO}_{2}$ and $\mathrm{PaO}_{2}$ were made at the beginning of the study together with mean arterial blood flow velocity (CBFV). We aimed to increase the $\mathrm{PaCO}_{2}$ by approximately $1 \mathrm{kPa}(7.5$ $\mathrm{mm} \mathrm{Hg}$ ) providing the initial $\mathrm{PaCO}_{2}$ was $7 \mathrm{kPa}(53 \mathrm{~mm} \mathrm{Hg})$ or less. This was done by placing a $5-$ to $10-\mathrm{ml}$ deadspace into the ventilator circuit close to the endotracheal tube. The infant was allowed to stabilize for $10 \mathrm{~min}$ before a repeat measurement of $\mathrm{PaCO}_{2}$ was made together with a second assessment of CBFV. Infants with severe lung disease and a high initial $\mathrm{PaCO}_{2}(>7$ $\mathrm{kPA},>53 \mathrm{~mm} \mathrm{Hg}$ ) were not included in the analysis.

Indomethacin study. Indomethacin $(0.2 \mathrm{mg} / \mathrm{kg})$ was used to treat infants with clinical signs of a patent ductus arteriosus who were ventilator dependent. The drug was infused intravenously over a 30 -s period. The effects of indomethacin on $\mathrm{CO}_{2}$ reactivity was assessed by performing the procedure described above 10 min after cessation of the infusion. This was compared to the $\mathrm{CO}_{2}$ reactivity measurements made immediately before the indomethacin was given. 
Measurement of $C B F V$. Doppler ultrasound recordings were made using an ATL 600 duplex Doppler system with a 727A probe (pulse-echo frequency 7.5 MHz, Doppler frequency 5.0 $\mathrm{MHz}$ ). Recordings were made from the anterior cerebral artery as it ascended from the internal carotid artery before it deviated anteriorly under the corpus callosum (7). The Doppler sample volume was set at $3 \mathrm{~mm}$, and the high-pass filter set at its lowest level $(100 \mathrm{~Hz})$. The output power was kept at a minimum consistent with recording an adequate signal and was never allowed to exceed $100 \mathrm{~mW} \mathrm{cm-2} \mathrm{spatial} \mathrm{peak} \mathrm{temporal} \mathrm{average.}$ Optimal Doppler signals were obtained by simultaneously listening to the audio signal and observing the sonogram in real-time while making minor adjustments to the probe position and the sample depth. An audio tape recording of 25 consecutive cardiac impulses was made and the signals subsequently analyzed off line by the method previously reported (8). The angle of insonation was always measured at the end of each study and recorded for the subsequent calculation of velocity. The angle was always less than $10^{\circ}$. The mean velocity over the cardiac cycle was estimated by halving the mean value of the maximum velocity over the cardiac cycle (9).

Analysis. The change in CBFV that occurred with the rise in $\mathrm{PaCO}_{2}$ was expressed as the change in velocity corrected for a 1 $\mathrm{kPa}$ rise, and the results are recorded in this manner. Where paired data were available the changes were expressed as a percentage rise (or fall) per $1 \mathrm{kPa}$ from the lower $\mathrm{PaCO}_{2}$ reading. Statistical analysis was performed using Spearman rank correlation and Wilcoxon matched pairs signed rank test.

\section{RESULTS}

Nineteen infants were studied on a total of 45 occasions and the patient details are shown in Table 1 . Gestational age ranged from 26 to $33 \mathrm{wk}$ and postnatal age from 4 to $200 \mathrm{~h}$ at the time of the study. There was a statistically significant relationship between $\mathrm{PaCO}_{2}$ and CBFV (Spearman rank correlation $0.31, p$ $<0.005$ ). There was an increase in $\mathrm{CBFV}$ with rising $\mathrm{PaCO}_{2}$ on 35 occasions (16 infants), no change in three (three infants), and a fall in velocity on seven occasions (six infants). The median change in $\mathrm{PaCO}_{2}$ was $1.05 \mathrm{kPa}$ (range 0.32-2.19) and the initial $\mathrm{PaCO}_{2}$ measurement showed a median value of $4.76 \mathrm{kPa}$ (range
2.83-7.0). The change in velocity for a standardized increase in $\mathrm{PaCO}_{2}$ of $1 \mathrm{kPa}$ varied between -3.5 and $10 \mathrm{~cm} / \mathrm{s}$ (median 1.75 $\mathrm{cm} / \mathrm{s}$ ).

Measurements of $\mathrm{PaO}_{2}$ were also made at each study. There was no consistent trend in the rise or fall of $\mathrm{PaO}_{2}$ with increasing $\mathrm{PaCO}_{2}(p<0.5)$ and we could show no difference between the $\mathrm{CO}_{2}$ reactivity of very immature infants (29 wk and less) compared to those of $30-33$ wk gestation $(p=0.26)$. Five infants had a 5-min Apgar score of 5 or less (see Table 1). The median rise in $\mathrm{CBFV}$ per $1 \mathrm{kPa}$ rise in $\mathrm{PaCO}_{2}$ in the asphyxiated group was $1.45 \mathrm{~cm} / \mathrm{s}$ compared to a median rise of 1.15 in 14 nonasphyxiated infants $(p=0.3)$.

Eight infants developed PVH diagnosed by real-time ultrasound. The grading of the PVH lesion referred to in Table 1 has been previously reported (10). The median change in CBFV for a $1 \mathrm{kPa}$ rise in $\mathrm{PaCO}_{2}$ in infants with no evidence of $\mathrm{PVH}$ at the time of the study was $1.24 \mathrm{~cm} / \mathrm{s}$ compared to a $0.85 \mathrm{~cm} / \mathrm{s}$ change in infants with PVH. This was not statistically significant $(p<0.2)$.

MAP data were available from 18 infants on 43 occasions and there was a statistically significant association between rise in MAP with increasing $\mathrm{PaCO}_{2}$ for the whole group (Spearman rank correlation $0.27, p<0.025$ ). In 31 studies the MAP increased with increasing $\mathrm{PaCO}_{2}$, in two studies there was no change in blood pressure, and in 11 studies the MAP fell with increasing $\mathrm{PaCO}_{2}$. Of the 11 studies where MAP fell, in only five (four infants) was there also a fall in CBFV and in one other study was there no change in CBFV. The other five studies showed an increase in CBFV despite falling MAP.

The data were analyzed separately to assess if the $\mathrm{CO}_{2}$ reactivity varied with postnatal age. All studies performed within the first $24 \mathrm{~h}$ were considered to be in the early group $(n=21)$ and those studied after $24 \mathrm{~h}$ were considered in the late group $(n=20)$. Data from only 41 studies were considered as those treated with indomethacin $(n=4)$ were excluded from this analysis. When more than one study was performed in either the early or late period, the one that was most comparable in terms of the change in $\mathrm{PaCO}_{2}$ with that in the other group was selected for comparison. The age in hours of the paired values are shown in Table 1. Figure $1 A$ and $B$ show the changes in $\mathrm{PaCO}_{2}$ and $\mathrm{CBFV}$ in the two groups. There was a statistically significant rise in CBFV in

Table 1. Details of infants assessed for carbon dioxide reactivity*

\begin{tabular}{|c|c|c|c|c|c|}
\hline Patient & $\begin{array}{l}\text { Gestational } \\
\text { age (wk) }\end{array}$ & $\begin{array}{l}\text { Body wt } \\
\text { (g) }\end{array}$ & $\begin{array}{l}\text { Apgar at } \\
5 \mathrm{~min}\end{array}$ & Age at each study (h) & Intracranial pathology \\
\hline 1 & 31 & 1520 & 5 & $\underline{3}, \underline{27}, \uparrow 120$ & PVH grade III, $48 \mathrm{~h}$ \\
\hline 2 & 27 & 990 & 8 & $\underline{12}, \overline{96}, \underline{120}$ & $\begin{array}{l}\text { PVH grade II } 60 \mathrm{~h} \\
\text { Prolonged flare }\end{array}$ \\
\hline 3 & 28 & 1060 & 8 & $\underline{21}, \underline{72}$ & Bilateral PVH grade III, $48 \mathrm{~h}$ \\
\hline 4 & 29 & 1170 & 8 & $\underline{20}, \overline{84}$ & Normal \\
\hline 5 & 29 & 1050 & 9 & $\overline{4}$ & PVH grade $\mathrm{I}, 4 \mathrm{~h}$ \\
\hline 6 & 26 & 850 & 5 & 4 & Normal \\
\hline 7 & 27 & 860 & 9 & 11 & Normal \\
\hline 8 & 28 & 1080 & 7 & 18 & PVH grade II, $48 \mathrm{~h}$ \\
\hline 9 & 30 & 1800 & 3 & 4,17 & Normal \\
\hline 10 & 32 & 2140 & 5 & $5, \underline{21}, \underline{46}$ & Normal \\
\hline 11 & 29 & 910 & 8 & $4, \overline{28}, \overline{48}, 72,120,148+$ & Normal \\
\hline 12 & 27 & 840 & 4 & $\underline{6}, 26, \overline{50}, 80$ & PVH grade II, $48 \mathrm{~h}$ \\
\hline 13 & 30 & 1690 & 8 & $\underline{1 \overline{4}}, \overline{43}$ & Normal \\
\hline 14 & 33 & 2010 & 9 & $\overline{17}$ & Normal \\
\hline 15 & 33 & 1570 & 6 & 19,120 & Normal \\
\hline 16 & 27 & 1010 & 8 & $\overline{5}, \overline{29}, 48$ & Normal \\
\hline 17 & 30 & 1500 & 8 & $\underline{16}, \underline{45}, 70$ & Normal \\
\hline 18 & 29 & 1090 & 6 & $\overline{24}, \overline{20}+\ddagger$ & Bilateral grade II PVH, 96 h \\
\hline 19 & 31 & 1830 & 6 & $17,120, \ddagger 144+$ & PVH grade II, $16 \mathrm{~h}$ \\
\hline
\end{tabular}

* PVH grading refers to that of Levene et al. (10) and the ultrasound appearances of prolonged flare has been described elsewhere (27).

$\dagger$ The ages underscored represent the paired early versus late data.

$\ddagger$ Denotes indomethacin studies. 
both groups with increasing $\mathrm{PaCO}_{2}$, but when MAP was considered for the early and late studies it failed to reach statistical significance (Table 2). The percentage change in velocity for tests performed within $24 \mathrm{~h}$ or less from birth could be expressed as a $44 \%$ rise in CBFV per $1 \mathrm{kPa}$ rise in $\mathrm{PaCO}_{2}(5.9 \%$ rise per $1 \mathrm{~mm}$ $\mathrm{Hg}$ ). There was a proportionately greater rise in CBFV in infants when studied after the first $24 \mathrm{~h}$ of birth. In this group there was a median rise of $53 \%$ in CBFV per $1 \mathrm{kPa}$ rise in $\mathrm{PaCO}_{2}(7 \%$ per $1 \mathrm{~mm} \mathrm{Hg}$ ).

Eleven infants had at least two studies; one within $24 \mathrm{~h}$ (early) and the other after $24 \mathrm{~h}$ (late). The percentage change in CBFV per $1 \mathrm{kPa}$ rise in $\mathrm{PaCO}_{2}$ was calculated for the early and late studies and the results are shown in Figure 2. In 10 of the 11 infants there was an increase in percentage reactivity with advancing age and this was statistically significant $(p<0.001)$. The change in MAP per $1 \mathrm{kPa}$ rise in $\mathrm{PaCO}_{2}$ was also analyzed in a similar manner. There was no significant difference in MAP changes between the early and late studies $(p=0.4)$.

The effects of indomethacin on $\mathrm{PaCO}_{2}$ reactivity was investigated on four occasions (three infants) as indicated in Table 1. These results are shown in Figure 3 and are expressed as a percentage change in CBFV per $1 \mathrm{kPa}$ rise in $\mathrm{PaCO}_{2}$. The median preindomethacin increase was $144 \%$ and $10 \mathrm{~min}$ after infusion, a $1 \mathrm{kPa}$ increase in $\mathrm{PaCO}_{2}$ caused the $\mathrm{CBFV}$ to increase by a median value of $49.5 \%$. Indomethacin appears to reduce $\mathrm{CO}_{2}$ reactivity in premature infants.
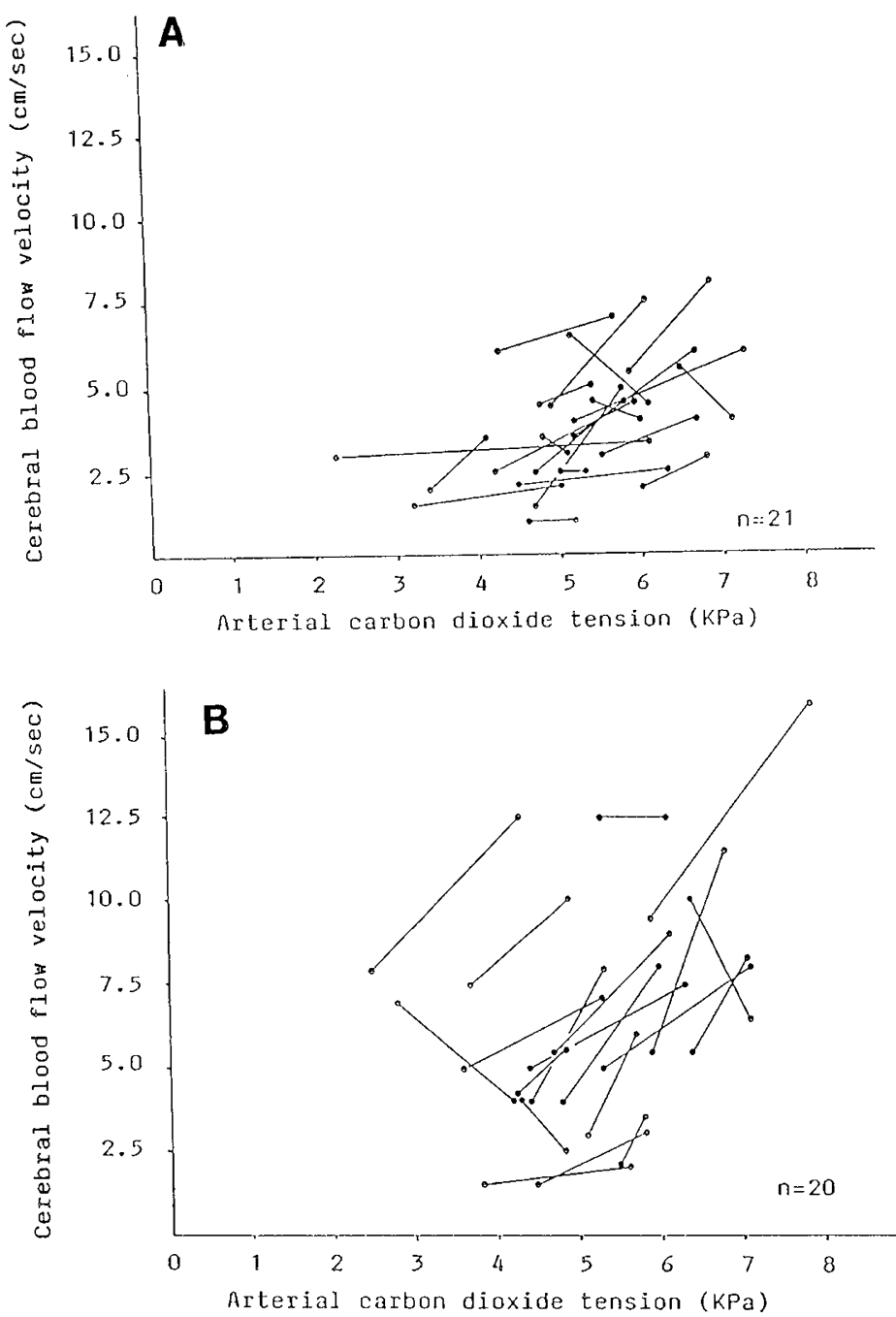

Fig. 1. Relationship between $\mathrm{PaCO}_{2}$ and $\mathrm{CBFV}$ in those infants with paired readings. $A$, those studied within the first $24 \mathrm{~h}$ of life. $B$, those studied after $24 \mathrm{~h}$ of life.
Table 2. Details of median (range) of the $\mathrm{PaCO}_{2}, \mathrm{CBFV}$ and MAP data for predeadspace (study 1) and postdeadspace (study

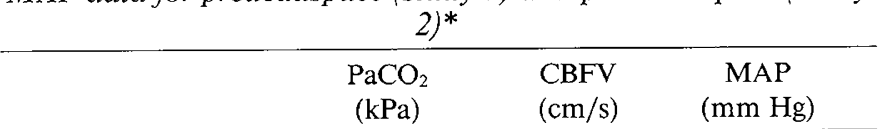

\begin{tabular}{cccc}
\hline Early recordings & & & \\
Study 1 & 4.78 & 6 & 38 \\
& $(3.24-6.51)$ & $(2-13)$ & $(22-62)$ \\
Study 2 & 5.75 & 9 & 40 \\
& $(4.10-6.98)$ & $(2-16)$ & $(20-58)$ \\
& & $\mathrm{p}=0.01$ & $\mathrm{p}=0.31$ \\
Late recordings & & & \\
Study 1 & 4.75 & 10 & 40.5 \\
& $(2.83-7.00)$ & $(3-25)$ & $(30-62)$ \\
Study 2 & 6.02 & 14.5 & 42 \\
& $(4.16-7.98)$ & $(4-32)$ & $(28-63)$ \\
& & $\mathrm{p}=0.002$ & $\mathrm{p}=0.23$ \\
\hline
\end{tabular}

* The early recordings were performed in the first $24 \mathrm{~h}$ and the late recordings done after $24 \mathrm{~h}$ from birth. The statistical analysis refers to comparison between study 1 and 2 .

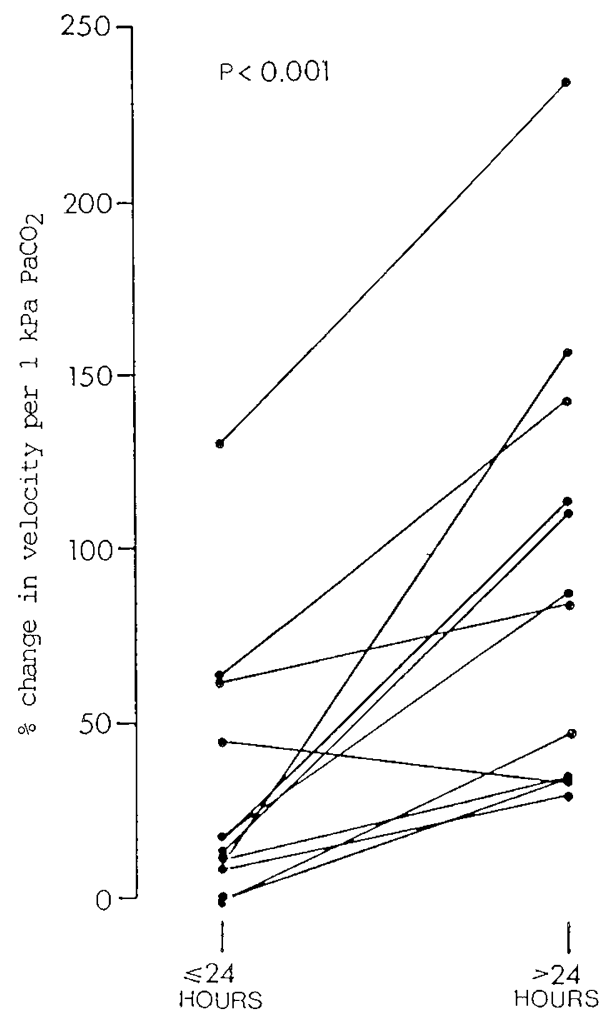

Fig. 2. Carbon dioxide reactivity and postnatal age. The change in $\mathrm{CBFV}$ is expressed as a percentage increase per $1 \mathrm{kPa}$ rise in $\mathrm{PaCO}_{2}$ for paired studies performed on 11 infants. The median age for the late study was $48 \mathrm{~h}$ (range $26-120 \mathrm{~h}$ ).

\section{DISCUSSION}

The observation that blood vessels react to changes in respiratory activity was made more than $100 \mathrm{yr}$ ago (11). The direct relationship between rising arterial tension of carbon dioxide and increasing CBF was first shown by Kety and Schmidt (12) and this is now well accepted. Hypoxia has a similar action on increasing $\mathrm{CBF}$ and the two appear to have an additive effect (13). The precise method by which the cerebral arterioles dilate in response to rising carbon dioxide tension is however less clear. There are probably at least two mechanisms. First, changes in the perivascular concentration of oxygen and carbon dioxide as 


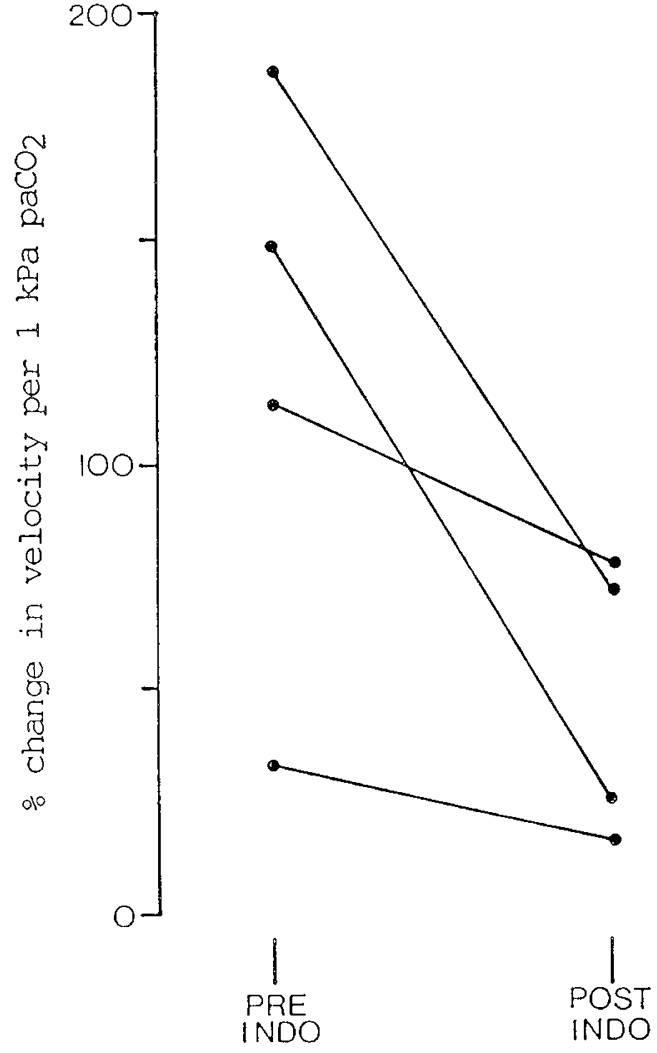

Fig. 3. Effects of indomethacin on $\mathrm{CO}_{2}$ reactivity in three infants. The change in CBFV corrected for a $1 \mathrm{kPa}$ rise in $\mathrm{PaCO}_{2}$ is expressed as a percentage of the low $\mathrm{PaCO}_{2}$ reading just before indomethacin infusion $(0.2 \mathrm{mg} / \mathrm{kg})$ and $10 \mathrm{~min}$ after infusion (postindomethacin).

well as acid-base status may directly affect the tone of the arterioles and second, chemoreceptors may influence vessel diameter through sympathetic afferents.

We have shown that even in the most immature and sick infants of 26 wk gestation their cerebral vessels react to changes in carbon dioxide tension. There was no consistent change in arterial oxygen tension and this could not have caused the observed changes in CBFV, and asphyxia did not appear to have an effect on the reactivity. The range of normal CBFV for very low birth weight infants has been previously reported (7). The median values on days 1 and 2 were 3.3 and $4.6 \mathrm{~cm} / \mathrm{s}$, respectively, and these are comparable to our recordings of 3.0 and 5 $\mathrm{cm} / \mathrm{s}$ for the normocapnic early and late recordings reported herein. These infants therefore do not have an abnormally low CBFV that might have accounted for the proportionately lower percentage change particularly seen in the first $24 \mathrm{~h}$.

The effects of hypercarbia on CBF in immature animals (14, $15)$ and newborn premature infants (16-18) have been reported before. The neonatal animal work suggests that the changes in $\mathrm{CBF}$ with hypercarbia are less well developed than in the adult animal $(14,15)$. Conversely, in the premature infant, the CBF response to rising $\mathrm{CO}_{2}$ suggests that the response is more exaggerated than that seen in the adult. An increase in CBF varying between $58.5 \%(16), 52 \%$, and $67 \%(17)$ per $1 \mathrm{KPa}$ rise in $\mathrm{CO}_{2}$ has been reported in premature infants. These results correspond to an increase of $7.8,6.9$, and $8.9 \%$ per $1 \mathrm{~mm} \mathrm{Hg}$ rise in $\mathrm{PaCO}_{2}$ and were obtained by using venous occlusion plethysmography (16) and intravenous Xenon (17) to measure CBF. These figures are remarkably similar to the $53 \%$ increase in $\mathrm{CBFV}$ per $1 \mathrm{KPa}$ rise in $\mathrm{PaCO}_{2}(7 \%$ per $1 \mathrm{~mm} \mathrm{Hg}$ ) reported herein for infants of comparable age to those previously reported. It is not clear why the immature infant has such an exaggerated response compared to the adult.
Although we found that for the whole group there was a statistically significant relationship between rising MAP and increasing $\mathrm{PaCO}_{2}$, when the early and late groups were studied separately this relationship no longer pertained, despite a continuing strong relationship between $\mathrm{PaCO}_{2}$ and $\mathrm{CBFV}$. In the 11 infants with paired early and late reactivity studies there was no significant relationship between MAP and $\mathrm{PaCO}_{2}$. It is unlikely that the changes in CBFV we have observed have occurred due to an increase in MAP in infants without the ability to autoregulate their cerebral circulation.

We have previously reported that there is an increase in $\mathrm{CBFV}$ over the first 2 to 3 days of life recorded from both the anterior and middle cerebral arteries (7). If this change reflects, as we believe it does, an increase in CBF it is of interest to speculate on the reasons for this. It is possible that the increase is due to a rise in cerebral metabolic rate and that the CBF increases to match this. We suggest that an alternative explanation is that the infant is born with a relatively vasoconstricted cerebral vascular bed. Dilatation occurs over the first few days with consequent fall in cerebral vascular resistance and rise in CBF. We believe that the data presented herein support this hypothesis.

In the early hours after birth the vasoconstricted cerebral vessels react less well to rising tension of carbon dioxide than the more dilated vessels after this time. Indomethacin is a powerful prostaglandin synthetase inhibitor, and prostaglandins have actions on the control of the cerebral circulation. Indomethacin causes a fall in CBF of up to $50 \%$ in mature animals $(19,20)$ and is also associated with a very rapid fall in CBFV in premature infants studied with Doppler ultrasound $(21,22)$. This fall in $\mathrm{CBF}$ is almost certainly due to cerebral arteriole vasoconstriction. It is also known that indomethacin causes dissociation between $\mathrm{CBF}$ and cerebral metabolic rate and there is no change in cerebral oxygen metabolism after indomethacin injection (23). We have taken advantage of the administration of intravenous indomethacin to assess the change to $\mathrm{CO}_{2}$ reactivity in three premature infants. On all four occasions there was a reduction in $\mathrm{CO}_{2}$ reactivity immediately after indomethacin administration. The median percentage change in reactivity after indomethacin was reduced by $67 \%$ which is similar to the reduction of $75 \%$ in an experimental animal (24). Because indomethacin does not reduce cerebral metabolic rate the only explanation for the fall in $\mathrm{CO}_{2}$ reactivity is vasoconstriction, and this is consistent with our hypothesis that we are seeing the effect of active vasodilatation in the first few days of life. The extremely large percentage change in CBFV before indomethacin infusion seen in two of our patients may be related to the hemodynamic effects of a patent ductus arteriosus, but the very few number of observations may equally account for this apparent anomaly.

$\mathrm{PVH}$ is a common condition in the extremely premature infant and occurs in the first few days of life (10). This is exactly the time that CBFV (and presumably CBF) is increasing rapidly and it is this rapid increase in flow that may be the causal factor in germinal matrix hemorrhage. Indomethacin has been shown to prevent PVH in both immature animals (25) and human infants (26) and it may exert its action by controlling the gradual vasodilation, thereby avoiding rapid fluctuations in CBF.

In conclusion we have shown that the cerebral arterioles in premature infants are capable of active changes in tone, but to a lesser extent in the first $24 \mathrm{~h}$ from birth than subsequently. Indomethacin also reduces the percentage change in $\mathrm{CO}_{2}$ reactivity. These findings are compatable with the hypothesis that the infant is born with a relatively vasoconstricted cerebral arteriolar bed and that active vasodilatation over the first few days of life is associated with a large increase in CBF and the attendant risk of PVH.

\section{REFEREINCES}

1. Purves MJ, James IM 1969 Observations on the control of cerebral blood flow in the sheep fetus and newborn lamb. Circ Res 25:651-667

2. Papile L-A, Rudolph AM, Heymann MA 1985 Autoregulation of cerebral 
blood flow in the preterm fetal lamb. Pediatr Res 19:159-16

3. Laptook R, Stonestreet BS, Oh W 1983 Brain blood flow and oxygen delivery during hemorrhagic hypotension in the piglet. Pediatr Res 17:77-82

4. Hernandez MJ. Brennan RW, Bowman GS 1980 Autoregulation of cerebral blood flow in the newborn dog. Brain Res 184:199-202

5. Archer LNJ, Evans DH, Paton JY, Levene MI 1986 Controlled hypercapnia and neonatal cerebral artery Doppler ultrasound waveforms. Pediatr Res 20:218-221

6. Evans DH, Lark GM, Archer LNJ, Levene MI 1986 The continuous measurement of intra-arterial pressure in the neonate-method and accuracy. Clin Phys Physiol Meas 7:179-184

7. Evans DH, Levene MI. Shortland DH, Archer LNJ 1988 Resistance index, blood flow velocity, and resistance-area product in the cerebral arteries of very low birth weight infants during the first week of life. Ultrasound Med Biol 14:103-110

8. Prytherch DR, Evans DH 1985 A versatile microcomputer based system for the capture, storage and processing of spectrum analyzed Doppler ultrasound blood flow signals. Med Biol Eng Comput 23:445-449

9. Evans DH 1985 On the measurement of the mean velocity of blood flow over the cardiac cycle using Doppler ultrasound. Ultrasound Med Biol 11:735741

10. Levene MI, Fawer C-L, Lamont RF 1982 Risk factors in the development of intraventricular haemorrhage. Arch Dis Child 57:410-417

11. Donders FC 1851 Die Bewegungen des Gehirns und die Veranderungen der Gefassfullung dere Pia mater. Schmid Fahrbucher 69:16-20

12. Kety SS, Schmidt CF 1948 The effects of altered arterial tensions of carbon dioxide and oxygen on cerebral blood flow and cerebral oxygen consumption of normal young men. J Clin Invest 27:484-492.

13. Shapiro W, Wasserman AJ, Patterson JL 1966 Human cerebrovascular response to combined hypoxia and hypercapnia. Circ Res 19:903-910

14. Reivich MAW, Brann H, Shapiro J, Rawson A, Sano N 1971 Reactivity of cerebral vessels to $\mathrm{CO} 2$ in the newborn rhesus monkey. Eur Neurol 6:132136

15. Hernandez MJ. Brennan RW, Vannucci RC, Bowman GS 1978 Cerebral blood flow and oxygen consumption in the newborn dog. Am $\mathrm{J}$ Physiol 234:R209-R215

16. Leahy FAN, Cates D, MacCullum M, Rigatto $\mathrm{H} 1980$ Effect of $\mathrm{CO}_{2}$ and $100 \%$ $\mathrm{O}_{2}$ on cerebral blood flow in preterm infants. J Appl Physiol 48:468-472

17. Greisen G, Trojaborg W 1987 Cerebral blood flow, $\mathrm{PaCO} 2$ changes and visual evoked potentials in mechanically ventilated, preterm infants. Acta Paediatr Scand 76:394-400

18. Daven JR. Milstein JM. Guthrie RD 1983 Cerebral vascular resistance in premature infants. Am J Dis Child 137:328-331

19. Sakabe T, Seisjo BK 1979 The effect of indomethacin on the blood flowmetabolism couple of the brain under normal, hypercapnic and hypoxic conditions. Acta Physiol Scand 107:283-284

20. Bedard MP. Kotagel UR, Kleinman LI 1983 Acute cardiovascular effects of indomethacin in anaethestised newborn dogs. Dev Pharmacol Ther 6:179186

21. Cowan F 1986 Acute effects of indomethacin on neonatal cerebral blood flow velocities. Early Hum Dev 13:343

22. Evans DH, Levene MI, Archer LNJ 1987 The effect of indomethacin on cerebral blood flow velocity in premature infants. Dev Med Child Neurol 29:776-782

23. Pickard JD, Mackenzie ET 1973 Inhibition of prostaglandin synthesis and the response of baboon cerebral circulation to carbon dioxide. Nature 245:187188

24. Dahlgren N, Nilsson B, Sakabe T, Siesjo BK 1981 The effect of indomethacin on cerebral blood flow and oxygen consumption in the rat at normal and increased carbon dioxide tensions. Acta Physiol Scand 111:475-485

25. Ment LR, Stewart WB, Scott DT, Duncan CC 1983 Beagle puppy model of intraventricular hemorrhage: randomized indomethacin prevention trial. Neurology 33:179-184

26. Ment LR 1985 Randomized indomethacin trial for prevention of intraventricular hemorrhage in very low birthweight infants. J Pediatr 107:937-943

27. Trounce JQ, Rutter N, Levene MI 1986 Periventricular leucomalacia and intraventricular haemorrhage in the preterm neonate. Arch Dis Child 61:1196-1202 